\section{Percepções e práticas de adolescentes grávidas e de familiares em relação à gestação}

\section{Pregnancy related perception and behavior of adolescents and their families}

\section{Abstract}

Objectives: to investigate information on perception and behavior of pregnant adolescents and their families related to current pregnancy.

Methods: descriptive study involving 19 pregnant adolescents from 10 to 19 years old under prenatal care in the family health units located in the Chié Island in Recife, from August to September 2002, and 14 family members and caretakers of these adolescents. Two collection tools were used and open questions were submitted to content analysis.

Results: adolescents are under the care of their mothers (71.5\%), experienced their first sexual intercourse with their boyfriends (85.7\%) when they were between 10-14 years old (52.7\%) using contraceptives $(68.4 \%)$ and have been pregnant before $(42.1 \%)$. Half of them accepted their current pregnancy, $78.5 \%$ receive financial and psychological support from the child's father and $57.2 \%$ from their mother. Before becoming pregnant $10.5 \%$ were not going to school or held a job, currently $57.9 \%$ are in this condition. Their caretakers are women, $21.4 \%$ illiterate and $64.3 \%$ support them. When informed of the pregnancy they were happy/satisfied (35.7\%) and unhappy (28.5\%), 92.9\% accepted the fact.

Conclusions: pregnancy during adolescence is not always perceived as a problem and that reinforces the value of designing prevention strategies considering local reality.

Key words Pregnancy in adolescence, Comprehensive health care, Evaluation
Celian Tereza Batista Lima 1

Katia Virginia de Oliveira Feliciano 2

Maria Francisca Santos Carvalho 3

Andréa Patrícia Pereira de Souza 4 Jacyana de Barros Correia Menabó 5 Laís Souza Ramos 6

Leila Faro Cassundé 7

Maria Helena Kovacs 8

1,5 Secretaria de Saúde do Recife. Unidade de Saúde da Família do Chié 2. Rua Guaianazes, 379. Campo Grande. Recife, PE, Brasil. CEP: $52.031-300$

2 Secretaria de Saúde de Pernambuco. Recife, PE, Brasil

3 Secretaria de Saúde do Recife. Diretoria Executiva de Atenção Básica. Recife, PE, Brasil

4,6,7 Secretaria de Saúde do Recife. Unidade de Saúde da Família, Chié 1. Recife, PE, Brasil

8 Faculdade de Ciências Médicas. Universidade de Pernambuco. Recife, PE, Brasil

\section{Resumo}

Objetivos: conhecer as percepções e práticas de adolescentes grávidas e de seus familiares em relação à gestação atual.

Métodos: estudo descritivo com 19 gestantes, de 10-19 anos que realizaram pré-natal nas unidades de saúde da família da ilha do Chié, em Recife, de agosto a setembro de 2002, e 14 responsáveis pelas adolescentes. Utilizaram-se dois instrumentos para coleta de dados e as questões abertas foram submetidas à análise de conteúdo.

Resultados: as adolescentes têm a mãe como responsável pelo cuidado $(71,5 \%)$, iniciaram-se sexualmente com o namorado $(73,7 \%)$, com idade entre 10-14 anos $(52,7 \%)$, usando método contraceptivo $(68,4 \%)$ e têm antecedentes reprodutivos $(42,1 \%)$. Metade desejava a gravidez atual, 78,5\% recebem apoio afetivo e financeiro do pai da criança e $57,2 \%$ da mãe. Antes de engravidar 10,5\% não estudavam, nem trabalhavam, e atualmente 57,9\% estão nessa condição. Suas responsáveis são mulheres, $21,4 \%$ analfabetas $e$ 64,3\% provem o sustento. Diante da gravidez das filhas sentiram alegria/satisfação $(35,7 \%)$ e desgosto (28,5\%), e 92,9\% aceitaram o fato.

Conclusões: a gravidez na adolescência nem sempre é percebida como um problema, o que reforça a importância da construção de estratégias de prevenção que considerem a realidade local.

Palavras-chave Gravidez na adolescência, Cuidados integrais de saúde, Avaliação 


\section{Introdução}

À medida que se transformam as expectativas em relação à adolescência 1 e que o modelo de prevenção das doenças passa a nortear as ações de saúde, ${ }^{2}$ mudam as apreciações sobre a maternidade da mulher adolescente. Nesse sentido Eisenstadt, citado por Groppo, ${ }^{3}$ ressalta o caráter extremamente especializado e orientado para o desempenho e a realização individual das sociedades modernas, atribuindo funções meramente "preparatórias" e de treinamento a essa fase da vida. Essa concepção fundamenta a demarcação da adolescência como uma etapa de transição para a vida adulta, que deve ser reservada prioritariamente aos estudos. Assim, a idade de 15 a 19 anos que, durante muito tempo, em particular nos seus últimos subgrupos etários, foi tida como a etapa ideal para engravidar, hoje, é considerada como sendo uma idade precoce para a mulher ter filhos. 1

Em um contexto em que se supõe que a adolescente não deveria engravidar, o crescimento da população de jovens no Brasil 4 e as transformações profundas na vivência da sexualidade nesse grupamento social têm propiciado o aumento da incidência de gravidez, o qual vem despertando ainda maior interesse devido ao declínio da fecundidade entre as mulheres de 20 e mais anos de idade. A Pesquisa Nacional sobre Demografia e Saúde, 5 realizada em 1996, mostrou que $18 \%$ das adolescentes brasileiras de 15 a 19 anos já tiveram pelo menos um filho ou estavam grávidas. Na cidade do Recife, no ano 2000, 0,92\% do total de recém-nascidos eram filhos de adolescentes com idade de 10 a 14 anos e 23,46\%, de 15 a 19 anos. 6 Os dados atualizados, em 2001, do cadastramento das famílias residentes na comunidade de Roda de Fogo, 7 situada no Recife, mostraram que $2,1 \%$ das adolescentes estavam grávidas e 6,1\% já eram mães, mas, entre aquelas de 15 a 19 anos esse percentual foi de 11,9\%.

Para tratar da questão da gravidez na adolescência, é comum recorrer a três qualificativos ${ }^{8}$ que remetem às noções de oportunidade, adequação, previsão e desejabilidade do evento: a) gravidez precoce - pressupõe uma idade mais adequada para ter filhos, isto é, a existência de um ponto ótimo de maturidade física e psicológica; b) gravidez nãoplanejada - resultante de um descuido, por omissão, falta de habilidade ou problema no uso de contraceptivos, solicita antevisão do risco associado à vida sexual ativa; e c) gravidez não-desejada - contraria as aspirações à felicidade naquele momento da vida. Essas noções, certamente, são permeadas pelos significados e valores atribuídos à juventude nos distintos contextos socioculturais e pela hegemonia do recurso ao enfoque de risco para hierarquizar os problemas e planejar as ações de saúde.

A visão preventivista apoia-se na identificação de fatores que estão associados a uma maior probabilidade de ocorrência dos eventos de saúde, sendo caracterizada pela pretensão de instituir o que é adequado para controlar a ocorrência desses eventos. ${ }^{2}$ A sua aplicação no âmbito da gravidez na adolescência pressupõe a necessidade de incorporar à dimensão biológica, as dimensões sociais e comportamentais. Assim, os estudos desenvolvidos nesse campo passam a ter como propósito estabelecer associações entre as características das pessoas ou do seu ambiente social e os comportamentos sexuais que aumentam o risco de engravidar.

$\mathrm{Na}$ complexa rede de inter-relações que configura a gravidez na adolescência, ganham destaque a impulsividade, o imediatismo, os sentimentos de onipotência e indestrutibilidade - próprios dessa fase da vida, a idade cada vez mais precoce da menarca e da iniciação sexual, a falta de informação sobre concepção e contracepção, a baixa auto-estima das jovens, a aspiração à maturidade para concorrer em nível de igualdade com os pais e o fato da gravidez fazer parte do projeto de vida, na tentativa de alcançar autonomia econômica e emocional em relação à família de origem. Além do mais, a não participação regular em grupos religiosos, a influência do grupo de iguais no processo de afirmação da identidade de gênero, a escolaridade dos pais e as relações familiares conflituosas. $9-12$

Nesta idéia de prevenção, as necessidades relacionadas com a gravidez e as condutas a serem adotadas para evitar filhos são definidas a priori, subestimando o fato de que a adolescência é uma maneira de viver historicamente construída, condicionada pela especificidade dos distintos meios sociais e culturais que são conformados, em uma realidade múltipla e complexa, pelas interações entre condições de vida, religião, gênero, etnia, geração, entre outros. Há que levar em conta que os adolescentes atribuem sentidos à forma de se identificar como masculino e feminino e à sexualidade, bem como têm aspirações diferentes acerca da procriação. Assim, esse processo de transição da infância para a vida adulta é concebido e vivido de forma distinta por cada pessoa e também pela mesma pessoa em momentos diversos. $3,13,14$

Nos estratos populares, em particular, independentemente do sexo, o desejo de ter um filho aparece mais cedo e existe uma enorme valorização da gravidez, mas, o significado que lhe é conferido difere de acordo com o contexto. Leal e Fachel,15 
em estudo com jovens de 15 a 19 anos de idade, residentes em bairros periféricos de Porto Alegre, encontraram uma forte valorização cultural da gravidez que aparecia, especialmente entre as moças, como uma estratégia de aliança, representando um elemento fundamental em uma rede de arranjos domésticos, de consangüinidade e prestígios sociais, não funcionando mais em termos da construção da identidade feminina. Já entre jovens de escolas públicas noturnas de São Paulo, Paiva16 constatou que a maternidade e a paternidade são essenciais para a construção da identidade de gênero e que, entre as moças, o desejo de ter um filho decorre da percepção da criança como sentido da vida, mesmo sem marido, assim, preocupam-se mais com o apoio da própria família do que com o apoio do pai da criança.

As condições materiais da existência e os significados e expectativas que cercam a gravidez, torna-a para umas adolescentes parte do projeto de vida, constituindo-se para outras em um evento não planejado, em uma surpresa desagradável que gera temores e conflitos ou acentua os já existentes. É preciso considerar o receio de assumir a gravidez diante dos familiares, do grupo de iguais e dos demais membros da rede de relações sociais e de enfrentar as novas responsabilidades trazidas por essa situação, que podem provocar mudanças profundas na vida cotidiana. Entre as mães adolescentes são mais freqüentes o abandono da escola, o afastamento do grupo de amigos e das atividades próprias da idade e as limitações de oportunidade de emprego.9,12 Nessas circunstâncias, adquirem relevância o aumento na freqüência de abortamentos provocados nesse grupo populacional, o início tardio12 e o número de consultas pré-natal menor do que o esperado. ${ }^{17}$

A família brasileira tem mostrado grande diversidade na sua composição e nas formas de sociabilidade que vigoram em seu interior, sendo inconteste que a necessidade de conciliar os projetos individuais com os projetos coletivos permeia toda vida doméstica, estando as reações e os modos de agir em relação à adolescente grávida vinculados à inserção social e ao ambiente cultural. Pesquisas mostraram a relação entre educação, pobreza e maternidade adolescente: apenas $23 \%$ das jovens que tiveram um filho antes dos 20 anos de idade haviam estudado além da oitava série, em comparação com $44 \%$ daquelas que não tiveram filhos. Adolescentes cuja renda familiar é inferior a um salário mínimo quase não têm chance de completar o segundo grau após o nascimento do filho. ${ }^{9}$ No entanto, constatou-se que jovens que não tinham problemas com a escola anteriormente à gravidez e que contavam com uma certa estrutura familiar de apoio tendiam a continuar os seus estudos após o parto. ${ }^{8}$

As reações da família diante da adolescente grávida tendem a ser contraditórias, sendo comum a sobreposição dos sentimentos de revolta, abandono e aceitação do "inevitável". No início, a rejeição à gravidez e o constrangimento podem levar a família a tomar atitudes radicais, tais como, expulsar a adolescente de casa, induzir ou forçar o aborto e impor responsabilidades, exigindo o casamento ou a união estável e a assunção da maternidade. Porém, pode ocorrer uma negociação em torno de quem vai assumir a criança/gravidez, essa pessoa pode ser o próprio pai ou mãe da criança, seus avós maternos ou qualquer outro parente que se responsabilize pela mesma. As adolescentes, também, podem morar com seus companheiros em cômodos anexos aos da família de um deles, mantendo vínculos justapostos de filhos e pais. 9,15

A socialização é realizada, simultaneamente, pela família, pela escola, pela igreja, pela mídia e pelo grupo de iguais, entretanto, a família é o primeiro grupo de referência e seus valores perpassam as definições de papéis diferenciados de acordo com o gênero e a idade, desde a infância.18 Se a família é vista como a unidade básica do processo de socialização, as relações intergeracionais permitem apreender a dimensão temporal da socialização, apontando o "desmapeamento" que sinaliza a coexistência do moderno e do arcaico como modelos orientadores de socialização. 19 Entre os legados transmitidos para as mulheres, são marcantes aqueles relacionados ao casamento, ao afeto e à sexualidade, com os conflitos intergeracionais decorrentes da associação de certas atitudes e comportamentos, por exemplo, a efetivação da vida sexual ativa da mulher sem a proteção do casamento, à transgressão das normas recomendadas pela cultura sexual brasileira tradicional, o que causa muito impacto sobre o cotidiano dos jovens.

Os resultados de pesquisa realizada, em 2001, pela Organização das Nações Unidas para Educação, a Ciência e a Cultura (UNESCO) em parceria com o Ministério da Saúde, em 14 capitais brasileiras, evidenciam a iniciação sexual cada vez mais precoce dos jovens, além da tendência aos namoros breves e mais intensos. ${ }^{20}$ Há ainda o "ficar", prática cujos sentidos se estruturam em torno do não compromisso, da eventualidade e da atração física, apresentando-se como um novo tipo de relacionamento cujos limites são demarcados pela virgindade e pela disponibilidade feminina. Isso, na prática, permitiria a diversificação das parce- 
rias casuais e uma maior freqüência de relações sexuais, aumentando a possibilidade de fazer sexo sem proteção. O "ficar", também, é associado ao risco de engravidar, em uma situação que não permite que haja discernimento sobre a paternidade. ${ }^{21}$

Um estudo realizado no Recife mostrou que convivem a valorização da virgindade feminina e a dissociação das esferas do prazer e do casamento, compatível com o ideário moderno do direito individual, submetendo a identidade feminina a novas exigências, ou seja, mudaram os critérios de aceitação da mulher adolescente pelas amigas, pois, em alguns grupos a virgindade já não se constitui em um valor positivo. ${ }^{21} \mathrm{~A}$ desvalorização da inexperiência sexual pelo grupo de iguais tem levado jovens de ambos os sexos a procurarem ter relações sexuais sem estarem suficientemente preparados para isso.22 Os diferentes padrões de relações afetivo-sexuais coexistem com a responsabilização da mulher na esfera da contracepção e as suas dificuldades para negociar o sexo seguro, quando não faz a opção pelo uso de métodos contraceptivos femininos.

Envolvidos desde muito cedo na complexa trama das decisões reprodutivas, os adolescentes necessitam participar de um processo educativo que lhes permita, por meio do resgate das respostas produzidas por quem está diretamente afetado, usufruir sua sexualidade de modo saudável, com respeito mútuo e sem discriminação de gênero. Esse ponto de vista torna essencial o desenvolvimento de uma prática dialógica entre todos aqueles que de algum modo estão comprometidos com a concepção nessa etapa da vida: o adolescente, o grupo de iguais, a família, a escola, o serviço de saúde e a comunidade. A equipe de saúde tem um lugar de destaque na educação para a sexualidade, incorporando a necessidade e a possibilidade de adotar uma atitude comunicativa que permita reforçar os vínculos de cooperação, em particular, com os adolescentes. ${ }^{21}$

Nessa perspectiva, este trabalho foi realizado para conhecer as percepções e as práticas de gestantes adolescentes e de familiares frente à gravidez, tendo como propósito obter subsídios para reorientar as ações voltadas para a saúde reprodutiva no âmbito da atenção integral na adolescência, adaptando-as às expectativas e valores presentes na realidade local, onde emergem as respostas para lidar com a questão. Espera-se, apesar da especificidade de seus resultados, que o trabalho possa ampliar o debate reflexivo sobre as vivências que perpassam a gestação nesse grupamento social e os contextos em que as mesmas encontram-se inseridas, propiciando uma maior compreensão sobre a necessidade de ir construindo com os outros os caminhos para efetuação das estratégias para a promoção e a prevenção em saúde.

\section{Métodos}

Estudo descritivo de corte transversal, realizado com 19 gestantes de 10 a 19 anos de idade, que no período de agosto a setembro de 2002 estavam realizando o pré-natal nas unidades de saúde da Ilha do Chié - comunidade de baixas condições de vida situada no bairro de Campo Grande, pertencente ao Distrito Sanitário II, da cidade do Recife, PE, Brasil - e 14 pessoas responsáveis pelos cuidados dessas adolescentes. Em maio de 2001 foi iniciada a implantação do Programa de Saúde da Família nessa localidade que, atualmente, conta com duas equipes compostas por duas médicas, duas enfermeiras, duas auxiliares de enfermagem, dez agentes comunitárias de saúde, uma odontóloga, uma auxiliar de consultório dentário e uma técnica em higiene dental.

De acordo com os dados da atualização do cadastramento das famílias realizado pelas agentes comunitárias de saúde, em junho 2002, a população adscrita corresponde, no Chié 1, a 2795 pessoas, das quais 532 são adolescentes de 10 a 19 anos de idade, $48,5 \%$ do sexo feminino e, no Chié 2 , a 2854 pessoas, das quais 507 são desse grupo populacional, 50,3\% do sexo feminino. Em 2002, no Chié 1, $37,5 \%$ do total de 56 gestantes que realizaram o prénatal eram menores de 20 anos de idade, todas tinham de 15 a 19 anos. No mesmo período, no Chié 2, $19,6 \%$ do total de 51 gestantes em acompanhamento pré-natal pertenciam a esse grupamento social, sendo que $3,9 \%$ tinham de 10 a 14 anos e $15,7 \%$ de 15 a 19 anos.

A coleta de informações foi feita utilizando dois instrumentos padronizados. Um para a adolescente grávida, aplicado pelas duas enfermeiras das equipes e uma fonoaudióloga que se associou a essas, com questões sobre identidade social, trajetórias sexual e reprodutiva, conhecimento sobre o período fértil, atividades antes e após a gestação, ${ }^{23}$ sentimentos e práticas frente à gravidez, percepções sobre os modos de agir da família e do parceiro e sugestões para prevenção da gravidez. Outro, para a pessoa que cuida da adolescente, aplicado pelas duas médicas e a dentista das equipes, com questões sobre características sócio-demográficas da família e da responsável, percepções, sentimentos e práticas diante da gravidez atual da adolescente, além de sugestões para prevenção da gestação. Os questionários foram respondidos de modo independente e os entrevistadores, para assegurar a padronização 
dos procedimentos na coleta de dados, foram devidamente treinados.

O projeto foi aprovado pelo Comitê de Ética em Pesquisa do Instituto Materno Infantil de Pernambuco, conforme o protocolo n. ${ }^{\circ} 125$ de 5 de agosto de 2002. As participantes foram esclarecidas quanto ao caráter espontâneo da participação e ao sigilo das informações, tendo sido solicitado o consentimento informado, que no caso das menores de 18 anos de idade foi assinado pelos seus responsáveis. As entrevistas foram feitas nas unidades, com as adolescentes, no momento da consulta do pré-natal ou em outro dia previamente agendado e com as responsáveis, em dia e hora marcados com antecedência pela agente comunitária da sua microárea de residência. Em duas situações, duas adolescentes eram filhas da mesma mãe, assim, 17 responsáveis deveriam ser entrevistadas, entretanto, três não puderam participar, duas do Chié 1, que sempre eram encontradas alcoolizadas, e uma do Chié 2, que havia viajado.

Após a coleta de dados todos os questionários foram revisados para identificar erros, omissões de respostas e deficiências na legibilidade dos registros. As respostas para as perguntas pré-codificadas com opção "Outras" foram listadas e receberam um código específico. Já as respostas às perguntas abertas que representam a forma mais elementar de dados qualitativos, 24 foram organizadas e estudadas para mapear os núcleos de sentido emergentes.25 Os temas que convergiam para um significado comum, com base nos critérios de homogeneidade interna, foram classificados em uma mesma categoria; simultaneamente, buscou-se garantir que as diferenças entre as distintas categorias fossem nítidas e claras, isto é, que houvesse heterogeneidade externa.

Para resgatar a intersubjetividade presente no processo de atribuição de significados, recorreu-se a dois procedimentos considerados essenciais para aumentar a confiabilidade da avaliação: 1) a utilização de um referencial teórico consistente apoiando a construção das categorias; e 2) o trabalho de mais de um avaliador, nesse caso foram quatro os avaliadores, afinando as possíveis divergências de interpretação. A análise temática foi encaminhada para a contagem de frequiência das unidades de significação, com estas variáveis sendo introduzidas nas duas matrizes de dados construídas utilizando o programa Epi-info 6.04.

Depois, foi feita uma listagem das freqüências das variáveis relacionadas com as adolescentes e as responsáveis. Os sentimentos e práticas frente à gravidez relatados pelas responsáveis foram cruzados com a situação conjugal das adolescentes. Dois aspectos merecem destaque nessa etapa: 1) a possi- bilidade de ocorrência de flutuações atribuíveis ao pequeno número de sujeitos entrevistados; e 2) a opção em algumas variáveis pela apresentação de todas as categorias de resposta, de modo que a tabulação retrata os dados originais, para evitar o obscurecimento de informações essenciais.

\section{Resultados}

A Tabela 1 mostra que uma adolescente tem entre 10 e 14 anos de idade, $57,9 \%$ cursaram de cinco a oito anos no sistema formal de educação e uma havia concluído o primeiro ano do curso universitário. Cerca de 47,4\% vivem com o companheiro $22,2 \%$ dos quais têm entre 15 e 19 anos - e uma é casada no civil. Em torno de $57,9 \%$ estão tendo a primeira gestação, enquanto, dentre as adolescentes com história de gravidez anterior, $62,5 \%$ têm antecedentes de abortamento e $62,5 \%$ de nascidos vivos - uma delas de três nascidos vivos. Não há referência a nascidos mortos.

A maior parte das adolescentes $(52,7 \%)$ fez sua iniciação sexual entre 10 e 14 anos de idade, mas, de acordo com a Tabela 2, apenas $10,5 \%$ tiveram a primeira relação entre 10 e 12 anos, enquanto, $63,2 \%$ dos parceiros tinham entre 15 e 19 anos. Para 94,7\% a iniciação ocorreu quando mantinham um relacionamento afetivo, sobretudo com o namorado, com duas terças partes querendo ter relação sexual naquele momento. Um percentual de de $68,4 \%$ das adolescentes dizem ter feito uso de método contraceptivo na primeira relação sexual. Os principais motivos para não evitar filhos foram a falta de expectativa quanto à relação sexual e à gravidez, entretanto, uma adolescente desejava ter filhos.

Somente uma adolescente tem informação correta sobre o período fértil. Um total de $73,6 \%$ considera apropriado o uso de métodos contraceptivos que são de responsabilidade da mulher, isto é, as injeções mensais $(31,6 \%)$, a esterilização feminina $(21,0 \%)$, as pílulas $(10,5 \%)$ e o dispositivo intrauterino $(10,5 \%)$. A "camisinha" e a esterilização masculina, métodos que são de responsabilidade do homem são referidos como sendo mais apropriados por, respectivamente, $21,0 \%$ e $5,3 \%$ das adolescentes. 
Tabela 1

Características sócio-demográficas das adolescentes grávidas. Ilha do Chié, Recife, PE, 2002.

\begin{tabular}{lcc}
\hline Características sócio-demográficas & (N = 19) & $\%$ \\
\hline Idade (anos) & 1 & 5,3 \\
$\quad 10-14$ & 18 & 94,7 \\
$15-19$ & 5 & 26,3 \\
Escolaridade (anos) & 11 & 57,9 \\
$\quad 1-4$ & 2 & 10,5 \\
$5-8$ & 1 & 5,3 \\
$9-11$ & & 5,2 \\
12 & 1 & 47,4 \\
Estado civil & 9 & 47,4 \\
$\quad$ Casada & 9 & 57,9 \\
$\quad$ Vive com companheiro & 11 & 62,5 \\
$\quad$ Solteira & 5 & 62,5 \\
Primeira gestação & 5 & - \\
Antecedentes de aborto* & - & \\
Antecedentes de nascidos vivos (1 a 3)* & & \\
Antecedentes de nascidos mortos* & & \\
\hline
\end{tabular}

* Excluídas 11 de primeira gestação.

Tabela 2

Características da iniciação sexual das adolescentes grávidas. Ilha do Chié, Recife, PE, 2002

\begin{tabular}{|c|c|c|}
\hline Iniciação sexual & $(N=19)$ & $\%$ \\
\hline \multicolumn{3}{|l|}{ Idade da adolescente } \\
\hline $10-12$ & 2 & 10,5 \\
\hline $13-14$ & 8 & 42,2 \\
\hline $15-17$ & 9 & 47,3 \\
\hline \multicolumn{3}{|l|}{ Idade do parceiro } \\
\hline $15-19$ & 12 & 63,2 \\
\hline $20-25$ & 5 & 26,3 \\
\hline Não sabe & 2 & 10,5 \\
\hline \multicolumn{3}{|l|}{ O parceiro era } \\
\hline Namorado & 14 & 73,7 \\
\hline Noivo & 2 & 10,5 \\
\hline Amigo & 2 & 10,5 \\
\hline Estranho & 1 & 5,3 \\
\hline Queria ter relações sexuais no momento* & 12 & 66,7 \\
\hline Evitou filhos & 13 & 68,4 \\
\hline \multicolumn{3}{|l|}{ Motivo para não evitar filhos $(n=6)$} \\
\hline Não esperava ter relação & 2 & 33,3 \\
\hline Não esperava engravidar & 2 & 33,3 \\
\hline Não dispunha de contraceptivo & 1 & 16,7 \\
\hline Queria ter filhos & 1 & 16,7 \\
\hline
\end{tabular}

* Excluída uma sem informação. 
Conforme a Tabela 3, o uso prévio de algum método contraceptivo é informado por $84,2 \%$ das adolescentes, a "camisinha" foi o primeiro método utilizado por $87,5 \%$ delas, $56,2 \%$ consideram que a preocupação com o uso do método deveria ser do casal e $25 \%$ da mulher. Metade recebeu orientações do parceiro sobre o uso de métodos contraceptivos e apenas uma adolescente foi orientada pelo médico. A outra metade tem obtido o método em farmácias e uma quarta parte em unidades de saúde. A falta de percepção sobre o risco de engravidar é o principal motivo para nunca haver utilizado qualquer método contraceptivo. Todas as adolescentes que utilizaram algum método já usaram "camisinha", ao menos uma vez na vida, 58,8\% para evitar a ocorrência, simul- taneamente, de gravidez e doenças sexualmente transmissíveis.

A Tabela 4 informa que o desejo de ter filhos foi o principal motivo para não evitar a gestação atual, seguido da recusa do companheiro em usar a "camisinha", mas, uma adolescente não conhecia nenhum método e outra faz referência à ocorrência de erro na utilização do contraceptivo. Aproximadamente metade das adolescentes desejava a gravidez. Um elevado percentual $(63,2 \%)$ diz que se sentiu muito feliz com a gravidez atual, mas $10,5 \%$ do total de adolescentes desejaram ou tentaram abortar. Ao ficarem grávidas, recorreram principalmente ao marido/companheiro e à mãe.

Tabela 3

Antecedentes do uso de métodos contraceptivos pelas adolescentes grávidas. Ilha do Chié, Recife, PE, 2002

\begin{tabular}{|c|c|c|}
\hline Uso de métodos & $(N=19)$ & $\%$ \\
\hline Já usou algum método contraceptivo & 16 & 84,3 \\
\hline "Camisinha" foi o primeiro método utilizado & 14 & 87,5 \\
\hline \multicolumn{3}{|l|}{ Preocupação com uso de um método } \\
\hline Os dois & 9 & 56,2 \\
\hline A própria & 4 & 25,0 \\
\hline Parceiro & 3 & 18,8 \\
\hline \multicolumn{3}{|l|}{ Orientou uso deste método } \\
\hline Marido/companheiro & 8 & 50,0 \\
\hline Professora & 2 & 12,5 \\
\hline Médico & 1 & 6,2 \\
\hline Outros & 3 & 18,8 \\
\hline Não sabe & 2 & 12,5 \\
\hline \multicolumn{3}{|l|}{ Obteve o método } \\
\hline Farmácia & 8 & 50,0 \\
\hline Unidade de saúde & 4 & 25,0 \\
\hline Pais & 1 & 6,2 \\
\hline Não sabe & 3 & 18,8 \\
\hline \multicolumn{3}{|l|}{ Motivo para nunca ter usado } \\
\hline Achava que não podia engravidar & 2 & 66,7 \\
\hline Não se preocupa com isso & 1 & 33,3 \\
\hline Já usou "camisinha" & 16 & 84,2 \\
\hline \multicolumn{3}{|l|}{ Motivo para usar "camisinha" } \\
\hline Evitar gravidez e DST & 10 & 58,8 \\
\hline Evitar gravidez & 4 & 23,5 \\
\hline Evitar DST & 2 & 11,8 \\
\hline Não sabe & 1 & 5,9 \\
\hline
\end{tabular}

DST = Doenças sexualmente transmissíveis 
Sentimentos e práticas das adolescentes frente à gestação atual. Ilha do Chié, Recife, PE, 2002.

\begin{tabular}{|c|c|c|}
\hline Sentimentos e práticas & $(N=19)$ & $\%$ \\
\hline \multicolumn{3}{|l|}{ Motivo para não evitar gravidez } \\
\hline Queria ter filho & 7 & 36,8 \\
\hline Companheiro não quis usar "camisinha" & 3 & 15,8 \\
\hline Não esperava ter relações & 2 & 10,5 \\
\hline Não se preocupou com isso & 2 & 10,5 \\
\hline Não esperava engravidar & 2 & 10,5 \\
\hline Não conhecia nenhum método & 1 & 5,3 \\
\hline Erro na utilização do método & 1 & 5,3 \\
\hline Não sabe & 1 & 5,3 \\
\hline \multicolumn{3}{|l|}{ Sentimentos frente à gravidez: } \\
\hline Ficou muito feliz & 12 & 63,2 \\
\hline Aceitou a gravidez sem casamento & 2 & 10,5 \\
\hline Desejou tentar fazer aborto & 2 & 10,5 \\
\hline Temeu reação do pai & 1 & 5,3 \\
\hline Não sabe & 2 & 10,5 \\
\hline Desejava a gravidez atual & 10 & 52,6 \\
\hline \multicolumn{3}{|l|}{ A quem recorreu quando ficou grávida } \\
\hline Marido/companheiro & 7 & 36,8 \\
\hline Mãe & 3 & 15,8 \\
\hline Pai e mãe & 3 & 15,8 \\
\hline Amiga & 3 & 15,8 \\
\hline Outro parente & 2 & 10,5 \\
\hline Ninguém & 1 & 5,3 \\
\hline
\end{tabular}

Na Tabela 5, observa-se que $89,5 \%$ estão recebendo assistência do pai da criança e, para a maioria (78,9\%), essa assistência é financeira e afetiva. Cerca de $63,2 \%$ das famílias estão dando apoio financeiro e afetivo à adolescente, com apenas uma adolescente referindo não receber qualquer tipo de ajuda. Aproximadamente $58,0 \%$ estão sendo apoiadas pela mãe e $21,0 \%$ pela mãe e o pai. Em $42,1 \%$ dos casos as famílias preferem não interferir nas decisões, mas, há a aceitação da gravidez sem casamento e o desejo de criar a criança.

A Tabela 6 indica que a gravidez provocou uma grande modificação no perfil de atividades das adolescentes, pois, $47,1 \%$ não estão mais realizando as mesmas atividades de antes da gestação. Metade das $52,6 \%$ que quando engravidaram só estudavam, deixou de estudar. Das quatro que só trabalhavam fora, apenas uma adolescente continua trabalhando. Uma, das três que estudavam e trabalhavam fora, abandonou o estudo e o trabalho. Quando engravidaram, $10,5 \%$ não estudavam nem trabalhavam e, atualmente, $57,9 \%$ encontram-se nessa situação. Os principais motivos alegados para essa mudança são o desejo de cuidar só da criança e o fato de estarem passando mal.

Todas as responsáveis pelos cuidados com as adolescentes são do sexo feminino, $71,5 \%$ é a própria mãe e as demais são irmãs $(14,3 \%)$, avó $(7,1 \%)$ e tia $(7,1 \%)$. Metade tem idade entre 35 e 44 anos e $35,7 \%$ já completaram 45 anos e mais. Uma quinta parte é analfabeta, $35,7 \%$ estudaram entre um a quatro anos e $35,7 \%$ entre cinco a oito anos no sistema formal de educação. Cerca de $50 \%$ estão casadas/vivem com o companheiro e $71,5 \%$ são católicas. Em torno de 71,5\% trabalham fora e $64,3 \%$ respondem pelo sustento da adolescente. Faz 20 anos e mais que $71,5 \%$ estão morando nesta comunidade. 
Percepções das adolescentes grávidas sobre o apoio recebido da rede social na gestação atual. Ilha do Chié, Recife, PE, 2002.

\begin{tabular}{|c|c|c|}
\hline Apoio social & $(N=19)$ & $\%$ \\
\hline \multicolumn{3}{|l|}{ Apoio recebido do pai da criança } \\
\hline Financeiro e afetivo & 15 & 78,9 \\
\hline Não dá apoio & 2 & 10,5 \\
\hline Só financeiro & 1 & 5,3 \\
\hline Só afetivo & 1 & 5,3 \\
\hline \multicolumn{3}{|l|}{ Apoio recebido da família } \\
\hline Financeiro e afetivo & 12 & 63,2 \\
\hline Só afetivo & 4 & 21,0 \\
\hline Só financeiro & 2 & 10,5 \\
\hline Não dá apoio & 1 & 5,3 \\
\hline \multicolumn{3}{|l|}{ Quem dá apoio } \\
\hline Mãe & 11 & 58,0 \\
\hline Mãe e pai & 4 & 21,0 \\
\hline Outros parentes & 4 & 21,0 \\
\hline \multicolumn{3}{|l|}{ Modo de agir da família } \\
\hline Não interfere & 8 & 42,1 \\
\hline Ajuda & 4 & 21,0 \\
\hline Aceita gravidez sem casamento & 3 & 15,8 \\
\hline Deseja criar a criança & 2 & 10,5 \\
\hline Outros & 2 & 10,5 \\
\hline
\end{tabular}

\section{Tabela 6}

A influência da gestação sobre as atividades das adolescentes grávidas. Ilha do Chié, Recife, PE, 2002.

\begin{tabular}{lcc}
\hline Atividades & (N = 19) & $\%$ \\
\hline Continua com a atividade* & 9 & 52,9 \\
Só estudava, quando engravidou & 10 & 52,6 \\
Só estuda, atualmente & 5 & 26,3 \\
Só trabalhava fora, quando engravidou & 4 & 21,0 \\
Só trabalha fora, atualmente & 1 & 5,3 \\
Estudava e trabalhava fora, quando engravidou & 3 & 15,8 \\
Estuda e trabalha fora, atualmente & 2 & 10,5 \\
Não estudava nem trabalhava fora, quando engravidou & 2 & 10,5 \\
Não estuda nem trabalha fora, atualmente & 11 & 57,9 \\
Motivo para não continuar com atividade $\quad$ & 37,5 \\
$\quad$ Quer cuidar só da criança & 3 & 37,5 \\
$\quad$ Está passando mal & 3 & 12,5 \\
$\quad$ Marido/companheiro não quer & 1 & 12,5 \\
\hline
\end{tabular}

* Excluídas duas sem informação. 
A Tabela 7 permite constatar que $57,1 \%$ das pessoas que responderam pelos cuidados tomaram conhecimento da gravidez atual das adolescentes por meio das mesmas, tendo a maioria sentido desgosto, rejeição e/ou tristeza diante do fato. Entretanto, $35,7 \%$ expressam sua alegria/satisfação com o acontecimento. Excluindo a que mandou dar a criança, as demais terminaram aceitando essa gravidez $(92,9 \%)$. A maioria aceita sem casamento e diz que deseja criar a criança. Um total de $42,9 \%$ mudaram de atitude no decorrer da gestação e essas mudanças são sempre relacionadas à melhoria dos cuidados dispensados à adolescente grávida e uma maior aceitação da gravidez.

A situação conjugal das adolescentes não teve qualquer influência sobre os sentimentos das responsáveis em relação à gravidez atual, assim, tanto aquelas que vivem com o companheiro, como as solteiras, despertaram alegria/satisfação, desgosto, tristeza, resignação e rejeição. No entanto, quando se considera o modo de agir da família, constata-se que apenas entre as adolescentes que estão solteiras $77,8 \%$ têm como parceiro o namorado ou o noivo uma recebeu ordem para dar o filho e outra a exigência de casamento.

Cerca de $68,4 \%$ das adolescentes oferecem sugestões para a prevenção da gravidez entre jovens, sendo as mais citadas: realizar palestras $(46,1 \%)$, orientar sobre sexualidade e prevenção da gravidez $(23,0 \%)$ e disponibilizar anticoncepcionais orais $(23,0 \%)$ e injetáveis $(15,3 \%)$, além de "camisinhas" $(15,3 \%)$. Para as responsáveis que dão sugestões $(92,9 \%)$, as principais são: educação sexual $(61,5 \%)$, planejamento familiar $(46,1 \%)$, ocupar o tempo dos adolescentes $(15,4 \%)$, fazer laqueadura após o parto $(15,4 \%)$ e realizar atividades de grupo com esse segmento populacional $(7,7 \%)$.

Tabela 7

Sentimentos e práticas das 14 responsáveis frente à gravidez atual das adolescentes. Ilha do Chié, Recife, PE, 2002.

\begin{tabular}{|c|c|c|}
\hline Sentimentos e práticas & $(N=14)$ & $\%$ \\
\hline \multicolumn{3}{|l|}{ Tomou conhecimento da gravidez } \\
\hline Ela contou & 8 & 57,1 \\
\hline Nunca foi informada & 2 & 14,3 \\
\hline Pai da criança & 2 & 14,3 \\
\hline Irmã & 1 & 7,1 \\
\hline Médico & 1 & 7,1 \\
\hline \multicolumn{3}{|l|}{ Sentimentos frente à gravidez } \\
\hline Alegria/satisfação & 5 & 35,7 \\
\hline Desgosto & 4 & 28,5 \\
\hline Rejeição & 3 & 21,4 \\
\hline Tristeza & 3 & 21,4 \\
\hline Indiferença & 1 & 7,1 \\
\hline \multicolumn{3}{|l|}{ Modo de agir frente à gravidez* } \\
\hline Aceita gravidez sem casamento & 5 & 35,7 \\
\hline Quer criar a criança & 5 & 35,7 \\
\hline Quer o casamento & 1 & 7,1 \\
\hline Mandou dar a criança & 1 & 7,1 \\
\hline Apóia a filha & 1 & 7,1 \\
\hline Não interfere & 1 & 7,1 \\
\hline Mudou de atitude no decorrer da gravidez & 6 & 42,9 \\
\hline \multicolumn{3}{|l|}{ Mudanças ocorridas no decorrer da gravidez $(\mathrm{N}=6)$} \\
\hline Aceitação & 2 & 33,3 \\
\hline Mais atenção/mais cuidado & 4 & 66,7 \\
\hline Mais carinho & 1 & 16,7 \\
\hline Mais tempo de sono para a adolescente & 1 & 16,7 \\
\hline Melhoria na alimentação & 1 & 16,7 \\
\hline Redução do trabalho doméstico & 1 & 16,7 \\
\hline
\end{tabular}

* Variáveis não mutuamente exclusivas. 


\section{Discussão}

Na ilha do Chié, pode-se observar a justaposição de características que mostram as precárias condições de vida das adolescentes estudadas, tais como, a participação de parentes respondendo pelos cuidados, as pessoas responsáveis, todas do sexo feminino, como únicas provedoras do sustento, apresentando alta frequiência de analfabetismo e baixa escolaridade. A grande vulnerabilidade social é reiterada pelas vivências da sexualidade, como a iniciação sexual precoce, sem proteção contra gravidez ou doenças sexualmente transmissíveis, a prática de abortamento, a gravidez atual como evento não planejado e as mudanças radicais das atividades após a gestação.

Semelhante aos resultados de pesquisas que mostraram como a primeira relação sexual entre adolescentes brasileiras está ocorrendo cada vez mais cedo,20 a maioria das participantes deste estudo tinha feito sua iniciação sexual entre 10 e 14 anos de idade, em geral, com parceiros adolescentes. Apesar da predominância do desejo de ter relações naquele momento, são bastante conhecidas as dificuldades da mulher para influenciar os rumos da primeira vez, circunstância em que a vontade masculina tende a preponderar, ainda que seja por meio da persistente solicitação de uma prova de amor e confiança que termina dando origem ao temor de perder o outro. Diante dos sentimentos e emoções que permeiam a vivência sexual-amorosa, torna-se muito mais difícil dizer não e conseguir estabelecer um pacto sobre a adequação do momento para ambos, assim como, concretizar a negociação para a prática de sexo seguro. 21

O início da vida sexual ativa aumenta a necessidade das adolescentes e seus parceiros agirem de forma que possam considerar as consequiências de seus atos, ou seja, a necessidade de tomar decisões informadas tendo uma perspectiva de futuro, portanto, com base nos seus sonhos e projetos de vida, os quais consubstanciam diferentes aspirações e possibilidades em decorrência dos padrões socioculturais de referência. Embora as opções pela forma, pelo ritmo das relações sexuais e pela prevenção da gravidez não sejam o resultado de uma decisão individual e solitária, mas o produto de uma interação em que as pessoas nem sempre estão movidas por interesses comuns, o homem continua mantendo um maior poder de negociação e decisão sobre as práticas sexuais. ${ }^{16,26}$

Em consonância com os valores que estão enraizados no imaginário social que atribui à mulher a responsabilidade pela prevenção da gravidez, 26 as adolescentes da ilha do Chié dizem ter preferência pelos métodos contraceptivos de uso feminino. Contudo, na prática, têm recebido mais orientações dos parceiros e têm utilizado, sobretudo, a "camisinha". Isso poderia se constituir em uma vantagem se a "camisinha" fosse utilizada de modo regular, permitindo a prevenção simultaneamente da ocorrência de gravidez e de doenças sexualmente transmissíveis. Porém, é possível que seja um indicativo de maiores impedimentos para a negociação do sexo seguro, já que: 1) a "camisinha" é um método masculino cuja utilização, em última instância, depende da vontade do homem que, com frequiência, prescinde do seu uso nos relacionamentos duradouros; 2) é bastante difundida a idéia de que a garantia da disponibilidade da "camisinha" no momento do ato está associada à imagem de masculinidade; e 3) são comuns os relatos femininos sobre a falta de habilidade dos homens para realizar os procedimentos adequados para o manuseio da "camisinha". 16,21,26

Essas dificuldades ficam explicitadas na recusa do parceiro como motivo para a não utilização de métodos contraceptivos e nos antecedentes de gestação e de práticas abortivas, inclusive, tendo sido mencionado o desejo ou tentativa de abortamento na gravidez atual. A elevada freqüência de aborto, nos estratos populares, pode resultar das negociações entre os parceiros em torno de assumir a criança/gravidez. 15 Entretanto, Paiva 16 constatou que as meninas dos cursos do ensino fundamental, sem recursos, tinham medo de não poder mais conceber, conhecida seqüela de aborto malfeito, em um meio de grande valorização da maternidade/paternidade. Já as jovens universitárias achavam mais tolerável corrigir uma gravidez não planejada com aborto, até porque nos estratos médios o aborto pode ser feito em condições médicas mais aceitáveis, embora constrangedoras, clandestinas e caras.

É premente abordar a maternidade adolescente, levando em conta as percepções masculinas sobre a vida reprodutiva e sexual, assim como, as aspirações dos adolescentes à paternidade. A responsabilização da mulher no campo das decisões reprodutivas pode fazer com que os homens sintam que são obrigados a modificar os rumos de suas vidas persuadidos pela necessidade de assumir um filho, antes que tenham a intenção de ser pai. ${ }^{26}$ Ressaltando as práticas educativas que estimulam a participação do homem nas decisões relativas à gravidez, Silva, citado por Oliveira (1998: 4), ${ }^{9}$ afirma: "... E aí não nos referimos apenas à mulher, mas a um processo que abranja a totalidade do ser humano e, com ela, o homem, parceiro e cúmplice, gerando uma relação de igualdade, que é o compromisso ético mais desejado da relação a dois". 
A questão da responsabilidade na vida sexual torna-se mais crítica durante a adolescência, quando moças e rapazes vivenciam as mudanças trazidas pela puberdade, a insegurança das primeiras atividades sexuais e a premência dos conflitos, das dúvidas e das urgências que perpassam a construção, sempre inacabada, da identidade. Essas experiências são vividas em meios socioculturais distintos, mas, imbuídos de grande ambigüidade na definição de direitos e deveres, de responsabilidades e independência, 13 quando o lidar de modo responsável com a sexualidade é parte de um processo mais amplo de aprendizagem que pressupõe a compreensão de que o jovem atribui sentidos às práticas, escolhe com base em preferências e estima o fim das suas ações. A capacidade de responder pelas próprias atitudes é desenvolvida ao longo do tempo e, como toda aprendizagem, implica em ter oportunidades para exercitar o discernimento diante dos sentimentos, impulsos, desejos e imprevistos que permeiam as relações entre as pessoas, assumindo pequenas responsabilidades, cometendo acertos e equívocos. 27

Não se pode tratar da mesma maneira a ocorrência da gravidez no grupo de 10 a 19 anos, pois, as moças de 15 a 19 anos, sobretudo nas últimas faixas etárias, têm reais aspirações reprodutivas, em particular nos estratos populares em que a maternidade é valorizada como forma de inserção social e de fortalecimento do vínculo com o companheiro. 15 A gestação, na ilha do Chié, é parte de um projeto de vida para grande quantidade das adolescentes que, por isso, sentem-se felizes, dizem que o desejo de ficar grávida foi o principal motivo para a não utilização de métodos contraceptivos e que abandonaram a escola e/ou trabalho para cuidar do filho. Mesmo as pessoas que cuidam dessas adolescentes, apesar da preponderância de sentimentos que denotam que a gravidez não se constituía em algo desejado para o momento atual, expressam alegria diante do fato. Nesse contexto, com freqüência, a gestação na adolescência não está sendo percebida como um problema, mas como um objetivo a ser alcançado.

As adolescentes e as suas responsáveis ressaltam aspectos distintos acerca dos modos de agir das famílias frente à gravidez. As meninas referem principalmente que não existe interferência nas decisões relacionadas com a gravidez atual, enquanto as responsáveis dão ênfase ao desejo de criar a criança e à aceitação da gravidez sem casamento. Apesar de receberem apoio material e afetivo do companheiro e da família, em particular da mãe, foram grandes as mudanças que a gestação provocou na vida dessas jovens. Em outra comunidade do Recife, com condições de vida similares, foi observado que a cir- cunstância de estar grávida ou ser mãe estava fortemente associada ao abandono da escola. ${ }^{7}$ No entanto, a associação entre a gravidez e o abandono da escola não é tão óbvia, mesmo porque é no processo de convivência doméstica que se definem os meios para enfrentar as dificuldades cotidianas, o que demanda dos integrantes da família um constante exercício para reorganizar as estratégias de conciliação entre as aspirações e os interesses individuais e coletivos. 18

Chama a atenção a pouca participação do setor saúde na rede de comunicação em que circulam as informações sobre a prevenção da gravidez nesse grupamento social. Em geral, a demanda de adolescentes para os serviços de saúde é pequena, mas, na ilha do Chié, desde abril de 2002, as agentes comunitárias fazem visitas domiciliares em que devem orientar as moças e os rapazes, entre outros aspectos, sobre contracepção e doenças sexualmente transmissíveis. A inibição do agente e/ou do adolescente para tratar de questões relacionadas à sexualidade diante de outras pessoas da família e a falta de preparo do agente para fornecer esse tipo de orientação, podem motivar as dificuldades existentes para o manejo desse conteúdo na prática educativa. Constatou-se que durante a visita domiciliar, adolescentes residentes em área de adscrição do Programa de Saúde da Família, localizada no Recife, recebiam pouquíssimas informações sobre sexo seguro e prevenção da gravidez. 28

Em contrapartida, com o propósito de contribuir para a melhoria da prevenção da gravidez, as responsáveis pelas adolescentes sugerem que sejam dadas mais orientações e priorizadas as atividades de planejamento familiar, enquanto as jovens solicitam orientações e acesso aos métodos contraceptivos. É inegável a complexidade da prevenção da gravidez na adolescência, pois, não se trata apenas de recorrer à pregação da abstinência sexual para adiar o início da vida sexual, tampouco, de informar sobre os métodos contraceptivos que são mais adequados para essa idade, mas, de assumir a prática educativa como um processo sistemático de orientação e reflexão sobre a sexualidade, trazendo condições para que rapazes e moças compreendam a relação entre as suas aspirações, a felicidade e a tomada de decisões sobre a vida sexual e reprodutiva. 8,29

Em suma, esses resultados reforçam a necessidade de conhecer melhor os sonhos e os ideais que orientam os projetos de vida dos adolescentes de ambos os sexos, integrando a escola, a família, as associações comunitárias e os serviços de saúde, na tentativa de construir, em conjunto, estratégias de prevenção que estejam mais próximas das necessidades geradas no contexto sociocultural em que esse grupo populacional está inserido. Desse modo, estaríamos 
ajudando a transformação da imagem ambígua do ser adolescente, facilitando para que se coloquem como protagonistas de um processo de mudança que lhes permitam uma vivência da sexualidade prazerosa e solidária, desenvolvendo uma relação consciente e negociada com as normas e os valores da família, do grupo de iguais e dos amigos.

\section{Referências}

1. Heilborn ML. Gravidez na adolescência: considerações preliminares sobre as dimensões culturais de um problema social. In: Vieira EM, Fernandes ME, Bailey P, McKay A, organizadores. Anais do Seminário Gravidez na Adolescência; 1998; Rio de Janeiro, RJ. Rio de Janeiro: Associação Saúde da Família; 1998. p. 23-32.

2. Reis AOA. Análise metafórico-metonímica do processo de constituição do pensamento da saúde pública acerca da adolescente grávida: os anos 60. Cad Saúde Pública 1998; [14 Supl 1]: 115-23.

3. Groppo LA. Juventude: ensaios sobre sociologia e história das juventudes modernas. Rio de Janeiro: DIFEL; 2000.

4. IBGE (Instituto Brasileiro de Geografia e Estatística). Censo: 2000. Disponível em: http://www.ibge.gov.br [5 fev 2004].

5. BEMFAM (Sociedade Civil Bem-Estar Familiar no Brasil) Adolescentes, jovens e a Pesquisa Nacional sobre Demografia e Saúde: um estudo sobre fecundidade, comportamento sexual e saúde reprodutiva. Rio de Janeiro: A Sociedade; 1999.

6. Recife. Secretaria de Saúde. Crianças do Recife: perfil de nascimentos - 1995-2000. Recife: A Secretaria; 2001

7. Figueiró AC. Condições de vida e saúde reprodutiva de adolescentes residentes na comunidade de Roda de Fogo, Recife. Rev Bras Saúde Matern Infant 2002; 2: 291-302.

8. Bock SD. A pregação da abstinência sexual - solução para a gravidez na adolescência? Bol GTPOS (Grupo de Trabalho e Pesquisa em Orientação Sexual) 1999; 17: 1-2.

9. Oliveira MW. Gravidez na adolescência: dimensões do problema. Cad Cedes [Centro de Estudos Educação e Sociedade]1998; 19: 48-70.

10. Cavalcanti SMOC, Amorim MMR, Santos LC. O significado da gravidez para a adolescente. Femina 2001; 29: 311-4.

11. Santos Jr JD. Fatores etiológicos relacionados à gravidez na adolescência: vulnerabilidade à maternidade. Cad Juv Saúde Desenvol 1999; 1: 223-9.

12. Ribeiro ACL, Uhlig, RFS. A gestação na adolescência e a importância da atenção à saúde do adolescente. Div Saúde Debate 2003; 26: 30-6.

13. Abramo HW. Contexto histórico e condição juvenil. In: Abramo HW. Cenas juvenis: punks e darks no espetáculo urbano. São Paulo: Serrita; 1994. p.1-53.

14. Margulis M. Juventud: una aproximación conceptual. In: Burak SD, organizador. Adolescencia y juventud en América Latina. Costa Rica: Libro Universitario Regional; 2001. p.41-56.

15. Leal OF, Fachel JMG. Jovens, sexualidades e estratégias matrimoniais. In: Heilborn ML, organizadora. Sexuali-

Recebido em 16 de julho de 2003

Versão final aprovada em 21 de outubro de 2003

Aprovado em 22 de dezembro de 2003 